\title{
The Application of Flipped Classroom in the Marketing Course Based on OBE Concept
}

\author{
Xin Zhang \\ Guilin University, Guilin, Guangxi, China
}

\begin{abstract}
Marketing course is a professional course with strong practicality. The author introduces flipped classroom based on OBE concept (outcome based education), as to enhance students' understanding on basic marketing knowledge, to practise their communication ability, to develop their recognition and pride of Chinese culture, and finally foster a talent suitable for community.
\end{abstract}

Keywords: Flipped classroom, OBE concept, Marketing, Wechat platform, Interaction between teachers and students.

\section{The Concept and Connotation of OBE}

OBE refers to Outcomes-based Education. Teaching activities based on OBE follow the design concept of "from the back to the front", that is, according to the steps of "determining expected learning Outcomes- realizing expected learning Outcomes - evaluating learning Outcomes". In the implementation of OBE education model, students' expected learning outcomes (i.e., teaching objectives) should be considered firstly. Then, certain teaching methods are used to carry out teaching activities. All teaching activities emphasize the concept of "teacher-guided, student-centered" and closely focus on the expected learning results of students. Students' learning outcomes at each stage will be assessed throughout the teaching process.

\section{Analysis of Teaching Mode of Traditional Marketing Course}

"Marketing" is a basic core course for E-commerce majors. It is a prerequisite for courses such as "Network Marketing", "Enterprise Marketing Planning" and "International Marketing". It is also one of the guiding courses for various college-level projects and competitions. This is an applied discipline based on economic science, behavioral science and modern management theory, which combines theory and practice closely. The course focuses on the process and regularity of enterprise marketing activities centering on meeting consumer demand and oriented by competition, that is, marketing activities are carried out by studying enterprise products, pricing, sales channel management and promotion. At present, the marketing course teaching process has the following situation: (1) Marketing has a strong professional. Marketing courses focus on specific marketing activities and require students to master and flexibly master basic marketing skills. However, no textbook can cover all aspects of marketing. As a result, marketing teaching content is relatively outdated and disconnected from practical operation. (2) Marketing knowledge learning is a process of active experience and construction. Knowledge cannot be acquired by teachers' one-way imparting, but by means of meaning construction in a specific context with the help of teachers and learning partners. However, some students lack subjective initiative and communication and cooperation ability. therefore, in view of the traditional "cramming" existing in the marketing course teaching, textbooks of teaching method, lay particular stress on the theoretical knowledge of immobilization, the problem such as lag of knowledge, teaching team needs from the curriculum content, curriculum teaching mode, curriculum evaluation reform, multiple Angle to improve students' learning initiative and cooperative innovation thinking, so that the students on the basis of the master the theoretical knowledge, Cultivate students' ability to correctly analyze and solve management problems in marketing activities, cultivate students' ability of new media operation and team communication, and cultivate applied marketing talents under the background of Internet economic development

\section{Practice of OBE Concept in the Interactive Learning Mode of Marketing}

Centering on the OBE teaching concept, the course team formulated and designed teaching activities according to the teaching objectives, carried out systematic and innovative reforms, and added modern enterprise marketing cases into the classroom content. In view of the problems of students' low enthusiasm in class and weak marketing practice skills, the team started from updating teaching methods, integrated information teaching methods, broke the traditional way of thinking, and built online mobile micro-classes through the Wechat public platform LIKETING to improve students' learning enthusiasm and subjective initiative. Fully cultivate students' independent learning ability, thinking ability, innovation ability and analysis and problem solving ability. According to comparative economics evaluation way stiff lagging problem, teaching team check method used in the curriculum innovation, guide students to form a team freely, the market marketing theory to help schools around the shops to solve business problems in the process of marketing, changed the disadvantages of disposable examination, strengthen the examination for the learning process, training students' ability to use multimedia marketing platform, And the practical application of marketing strategies.

\subsection{Remodeling and Optimization of Teaching Content}

Through the course reform and construction for many times and the improvement of the use of online mobile micro-classroom, the teaching team remodeled and optimized the original course structure, and re-upgraded the teaching content and resources

The teaching team, according to the current marketing theory 
into the modern enterprise marketing case, the construction of globalization and localization of marketing scenarios, including English, Japanese, Korean, French and German printing of China and the United States and other countries contain daily chemical products, high-tech industry, automotive, industrial manufacturing and service industries excellent cases, and accumulated more than 200 video, develop students' global perspective, in-depth marketing knowledge.

Introduced information technology in the classroom teaching process, established Wechat public account, encouraged the student team to collect, organize and share marketing news, accumulated more than 1000 times of subscriptions, published 132 marketing news tweets, trained students' new media operation skills and improved practical operation ability. The operation of information technology means also stimulates the enthusiasm of students to participate in various competitions. In the past two semesters, under the guidance of the teaching team, a total of 4 teams have won the approval of guangxi District-level college students' innovation and entrepreneurship projects.

The course assessment is changed from the traditional closed-book method to the group report, guiding students to apply the basic theory of marketing, observe the actual market environment, and use marketing methods to help businesses improve product and service quality, increase turnover and profit, and achieve sustainable development. In the past two semesters, a total of 30 teams helped 38 small and medium-sized shops solve marketing difficulties, trained students' ability to solve marketing problems, and trained applied marketing talents with correct values.

\subsection{The Teaching Mode is Changed to Online and Offline Interactive}

The teaching team strictly follows the teaching mode of "theoretical knowledge learning - practice case guidance new media operation", which is to refine theoretical knowledge content in class, expand global marketing vision based on case teaching, and assist students to push marketing news after class.

Based on Guangxi, the teaching team is committed to training applied talents for local economic development. Based on the existing basic theories of marketing and integrated with modern enterprise marketing cases, the teaching team constructs global and local marketing scenarios, expands students' global vision and deepens their learning of marketing knowledge.

\subsection{Change of Course Score Assessment into "Highlighting Cooperation Process"}

Marketing course has undergone several teaching reforms. According to marketing learning objectives and application talent training standards, in-depth teaching reform has been carried out to optimize course assessment methods, forming process assessment (80\%) + result assessment (20\%) assessment methods, quantifying assessment and scoring requirements, and emphasizing the importance of participation in the process.
Process evaluation (80\%) includes new media operation ability $(30 \%)+$ team project report $(30 \%)$ + classroom performance $(20 \%)$; Result evaluation $(20 \%)$ is the personal marketing summary, that is, students report the task completion in the process of assessment, problems in the process of team cooperation and solutions.

\subsection{Evaluation of Teaching Reform}

After the teaching reform of marketing course by the team in recent years, the teaching objectives of the course can be smoothly realized and constantly optimized, effectively guide students to change their learning mode from passive acquisition of knowledge to active absorption of knowledge, and improve students' learning enthusiasm, independent learning enthusiasm and practical operation ability. At the same time, through the integration of university teaching knowledge and new media technology, further tap students' learning potential and future development motivation. "Marketing" teaching contents breakthrough the traditional theory of knowledge, increase applied knowledge training, students can master all kinds of marketing strategy, and take an active part in all kinds of skills contest, Isaiah, whereas a won the first prize in the national competition, second prize, first prize in the district, three second prize of good grades. One team won the national College Student innovation and entrepreneurship project, and three teams won the district-level project.

\section{The Direction of In-depth Reform of Online and Offline Interactive Teaching Mode}

\subsection{The Plan of Course Continuous Construction and Further Problems to be Solved}

Marketing is a professional core course highlighting practical application ability, emphasizing the cultivation of students' operational ability. In today's rapidly changing marketing environment, the teaching team will further deepen the reform of course teaching:

\subsubsection{Teaching content needs to be reformed}

First of all, marketing is a highly comprehensive applied discipline, and the analysis of modern enterprise development needs to keep pace with The Times. However, based on the current situation of marketing courses, $85 \%$ of the teaching cases come from developed economies such as Britain and the United States, focusing on the analysis of enterprises in capitalist countries that applied the traditional mode of development in the first and second industrial Revolution. Marketing courses aim to cultivate applied talents who conform to the law of market development and adapt to and change the marketing mode through continuous reform. Therefore, it is particularly critical to add marketing cases of enterprises with innovative ability in the era of Internet economy in the course. Secondly, the design of teaching content attaches more importance to theory than to practice. Too much emphasis on theoretical teaching, boring classroom, ignoring the training of students' practical ability and the corresponding professional ability. The current curriculum focuses on theoretical knowledge (teaching content \& GT; $65 \%$ ), ignoring students' dominant position, resulting in 
students' low enthusiasm in class, thus restricting the cultivation and improvement of students' marketing practice skills.

\subsubsection{Teaching methods and methods need to be reformed}

Traditional teaching methods are still dominant. Although the team teachers use PPT and Wechat to teach in class, the teaching means of auxiliary teaching should be more diversified as the technology, network, intelligence and other technologies are constantly updated.

\subsection{Direction and Measures for Reform}

\subsubsection{Course resource construction is updated synchronously}

The team will follow the Harvard Business Review to explore and collect the Business miracles created by emerging economies, mainly China, in the challenging global economic environment since the third Industrial Revolution, and integrate the theoretical knowledge of marketing. The course content is changed into the course mode of "focusing on understanding the development mode of Chinese enterprises and solving the problems of modern enterprise marketing", which combines theory and practice to improve students' understanding and understanding of the global market and broaden their horizons of marketing knowledge.

\subsubsection{Student-led teaching methods}

The teaching team plans to introduce PBL (Problem-based Learning) Learning methods. "Problem-based learning" is a kind of teaching mode that takes practical problems or real cases as guidance, places teaching in a series of problem situations, and guides students to solve practical problems in the form of teamwork, so as to learn the real knowledge in problem situations and cultivate the ability of independent inquiry. PBL teaching can also cultivate and stimulate students' motivation for autonomous learning, so as to improve students' teamwork ability and autonomous inquiry learning ability.

\subsection{Informatization into Offline Classroom Teaching}

The teaching team will explore information technology means and timely collect students' learning effect and evaluation, which is conducive to the team to timely update the teaching structure and content.

\section{Conclusion}

Based on OBE concept, traditional Marketing course embraces new technology such as Wechat platform to enhance student's understanding on basic marketing knowledge and techniques, to practise their communication ability, to develop their recognition and pride of Chinese culture, and finally foster a talent suitable for society.

\section{References}

[1] Topf, J. M. (2020). Introduction: social media and medical education come of age. Seminars in Nephrology, 40(3), 247-248.
[2] Harden, \& Ronald, M. (2007). Outcome-based education: the future is today. Medical Teacher, 29(7), 625-629.

[3] Dai, Z. (2014). Reform and enlightenment of outcome-based education in Hong Kong Universities. Modern Distance Education Research.

\section{Author Profile}

Xin Zhang received the B.A. degree in International Business Management from University of Nottingham Ningbo, China, in 2013 and the M.S. degree in International Business and Emerging Markets from University of Edinburgh in 2014. She is currently working as the lecturer in the Department International Economy and Trade, Guilin University, Guilin, China. Her research interests is marketing and management in China. 